\title{
Implikasi Perkembangan Pariwisata Terhadap Sosial Ekonomi Masyarakat Di Desa Sibunga - Bunga, Kecamatan Sinembah Tanjung Muda (STM) Hulu, Kabupaten Deli Serdang, Sumatera Utara
}

Rio Sulistia Darma a, 1, Luh Putu Kerti Pujani a, 2

${ }^{1}$ rio_std@yahoo.com, ${ }^{2}$ kerti_pujani@unud.ac.id

aprogram Studi S1 DestinasiPariwisata, FakultasPariwisata,UniversitasUdayana, Jl. Dr. R. Goris, Denpasar, Bali 80232 Indonesia

\section{Abstract}

Tourism development will trigger positive or negative implication to the local communities. In term of socioeconomic, Sibunga-bunga village is one of the village which has been affected by tourism development. It can be seen from the increasing number of local people who leave the agricultural sector and turn to the tourism sector. The aim of this research is to know the tourism development phase and socio-economic implication to the people of Sibungabunga village.

The Data were collected through observational, interviews, and documentations, those data were described qualitatively. The tourism life cycle theory (TLCT) is proposed and tested in order to identify the tourism development phase. The socio-economic implications are presented with pictures to get a clear understanding of the facts and findings.

The result of the study shows that the tourism development phase of sibunga-bunga village is on involvement. Tourism development of Sibunga-bunga village has positive implications to create job opportunities, to increase local's income. Unfortunately, it was followed by negative impatcs such as in the form of violations of rules set by the managers of tourist attraction which may damage the surrounding environment,

Keywords : Tourism development, implication, socio-economic, Sibunga-bunga village

\section{PENDAHULUAN}

Pariwisata adalah suatu bentuk kegiatan yang menyentuh dan melibatkan masyarakat secara langsung, sehingga memberikan berbagai dampak terhadap masyarakat setempat. Bahkan pariwisata mempunyai energi dobrak yang luar biasa, yang mampu membuat masyarakat setempat mengalami metamorfose dalam berbagai aspek (Pitana \& Gayatri, 2005). Hal tersebut juga terjadi dalam proses perkembangan pariwisata di Desa Sibunga-bunga.

Desa Sibunga-bunga terletak di Kecamatan Sinembah Tanjung Muda (STM) Hulu, Kabupaten Deli Serdang, Sumatera Utara. Perkembangan pariwisata di Sumatera Utara tidak terlepas dari penetapan Danau Toba sebagai salah satu dari 10 destinasi wisata yang menjadi prioritas pengembangan pariwisata di Indonesia diantaranya, Danau Toba (Sumatera Utara), Tanjung Kelayang (Bangka Belitung), Kepulauan Seribu (DKI Jakarta), Tanjung Lesung (Banten), Borobudur (Jawa Tengah), Bromo-Tengger-Semeru (Jawa Timur), Wakatobi (Sulawesi Tenggara), Labuan Bajo (Nusa Tenggara Timur), Mandalika (Nusa Tenggara Barat), dan Pulau Morotai (Maluku Utara), yang diharapkan mampu menarik perhatian wisatawan domestik maupun mancanegara.
Melihat peluang yang ada, tidak menutup kemungkinan dengan dijadikannya Danau Toba sebagai salah satu destinasi wisata unggulan akan berdampak pada daya tarik wisata lainnya yang ada di Sumatera Utara, tak terkecuali bagi Desa Sibunga-bunga, dimana terdapat berbagai Daya Tarik Wisata seperti Danau Linting dan Goa Tao Delapan Puteri. Danau Linting telah ditetapkan menjadi salah satu kawasan wisata pada tahun 1999, berdasarkan Surat Keputusan Bupati Kepala Daerah Tingkat II Deli Serdang Nomor 556/272/DS/Tahun 1999. Namun berkembangnya pariwisata di Danau Linting baru dimulai sejak tahun 2012 yang ditandai dengan dibentuknya Kelompok Sadar Wisata (POKDARWIS) pada tahun 2012 dan terus berkembang hingga sampai saat ini.

Perkembangan pariwisata di Desa Sibunga-bunga memberikan berbagai implikasi positif bagi perekonomian masyarakat di Desa Sibunga-bunga, dengan membuka peluang kerja baru, sehingga sebagian masyarakat sudah mulai meninggalkan sektor pertanian dan beralih ke sector paiwisata sebagai pedagang dan penyewa pondok wisata. Selain itu, perkembangan pariwisata juga memberikan berbagai impliklasi negatif dalam bentuk pelanggaran aturan yang telah ditetapkan pengelola Daya Tarik Wisata berkaitan dengan aturan mendirikan bangunan sehingga berdampak pada kenyamanan wisatawan. 
Berdasarkan latar belakang diatas, rumusan masalah dalam penelitian ini yaitu bagaimana perkembangan pariwisata di Desa Sibungabunga dan bagaimana implikasi perkembangan pariwisata terhadap sosial ekonomi masyarakat di Desa Sibunga-bunga.

\section{TINJAUAN PUSTAKA}

Penelitian ini menggunakan beberapa konsep dan teori analisis diantaranya:

1. Konsep Implikasi menurut Shadily (1989) dalam Permilasari (2014) adalah suatu keadaan terpengaruh terhadap suatu masalah dalam kehidupan masyarakat.

2. Konsep Perkembangan menurut Warner dalam Jahja (2011) adalah suatu proses perubahan yang bersifat tetap dan tidak dapat diputar atau diulang kembali.

3. Konsep Atraksi Wisata menurut Suwena dan Widyatmaja (2010) membagi Atraksi wisata menjadi tiga yaitu atraksi wisata alam, atraksi wisata budaya dan atraksi wisata buatan.

4. Konsep Fasilitas menurut Suwena dan Widyatmaja (2010) adalah segala macam sarana dan prasarana yang dibutuhkan oleh wisatawan selama berada di daerah tujuan wisata.

5. Konsep Partisipasi menurut Soekanto (2005) adalah suatu bentuk pola prilaku ikut serta yang diharapkan dari seseorang yang memiliki status dan berkedudkan dalam suatu perusahaan atau organisasi.

6. Konsep Sosial Ekonomi menurut Cohen (1984) dalam Pitana (2005) membagi dampak perkembangan pariwisata terhadap sosial ekonomi masyarakat menjadi delapan kategori diantaranya : 1)dampak terhadap penerimaan devisa, 2)dampak terhadap pendapatan masyarakat, 3)dampak terhadap kesempatan kerja, 4)dampak terhadap harga-harga, 5)dampak terhadap distribusi manfaat/keuntungan, 6)dampak terhadap kepemilikan kontrol, 7)dampak terhadap pembangunan pada umumnya, dan 8)dampak terhadap pendapatan pemerintah.

7. Teori Destination Area Life Cycle menurut Butler (1980) dalam Pitana (2005) terbagi menjadi tujuh fase diantaranya : Exploration (Penemuan), Involvements (Keterlibatan), Development (Pembangunan), Consolidation (Konsolidasi), Stagnation (Stagnasi), Decline (Penurunan), Rejuvenation (Peremajaan).

\section{METODE}

Lokasi penelitian ini terletak di Desa Sibunga-bunga, Kecamatan Sinembah Tanjung Muda (STM) Hulu, Kabupaten Deli Serdang, Sumatera Utara. Adapun ruang lingkup dalam penelitian ini yaitu :

1. Perkembangan pariwisata di Desa Sibunga-bunga ditinjau dari beberapa aspek sebagai berikut :
a) Tingkat Kunjungan Wisatawan
b) Atraksi Wisata
c) Fasilitas
d) Partisipasi Masyarakat

2. Implikasi perkembangan pariwisata di Desa Sibunga-bunga ditinjau dari aspek sosial ekonomi diantaranya :

a) Peluang Kerja

b) Pelanggaran aturan

c) Pendapatan Masyarakat

Jenis data dalam penelitian ini menggunakan data kualitatif menurut Yusuf (2014). Data Kualitatif diantaranya, gambaran umum lokasi penelitian, perkembangan pariwisata di Desa Sibunga-bunga terkait dengan tingkat kunjungan wisatawan, atraksi wisata, fasilitas, dan partisipasi masyarakat, serta implikasi perkembangan pariwisata terkait sosial ekonomi masyarakat diantaranya, peluang kerja, pendapatan masyarakat, dan penyimpangan sosial. Data primer dalam penelitian ini adalah data tentang perkembangan pariwisata seperti atraksi wisata, fasilitas, dan partisipasi masyarakat, serta implikasi perkembangan pariwisata terhadap sosial ekonomi masyarkat. Data skunder terkait dengan profil Desa Sibungabunga.

Teknik pengumpulan data dalam penelitian ini menggunakan Observasi menurut Echols dan Shadily dalam Ibrahim (2015), Wawancara menurut Kartono dalam Gunawan (2015), dan Dokumentasi menurut Indrawan dan Yaniawati (2014). Penentuan informan dilakukan dengan menggunakan prosedur purposif menurut Bungin (2007) yang menentukan informan berdasarkan kriteria tertentu sesuai dengan fokus penelitian. Teknik analisis data dalam penelitian ini menggunakan teknik deskriptif kualitatif menurut Sugiyono (2014) yaitu mereduksi data, penyajian data, dan penarikan kesimpulan atau verifikasi. 


\section{HASIL DAN PEMBAHASAN}

Desa Sibunga-bunga merupakan salah satu diantara 20 desa yang berada di Kecamatan Sinembah Tanjung Muda (STM) Hulu, Kabupaten Deli Serdang. Secara administratif batas wilayah Desa Sibungabunga adalah sebagai berikut :

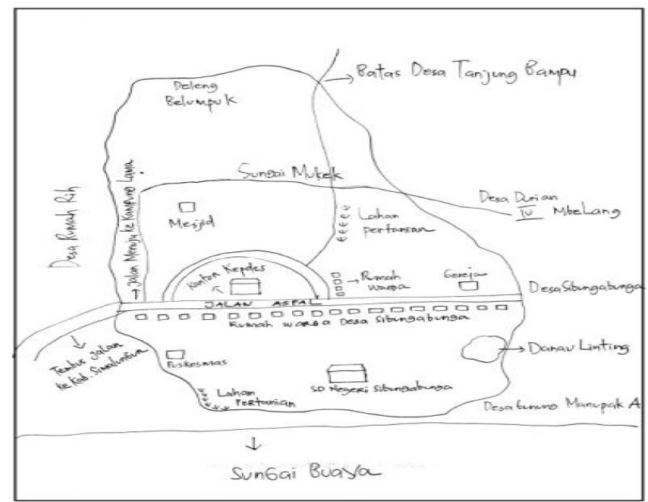

Sumber : Barus, Patana dan Afifuddin, 2013
a. Bagian Utara : Desa Gunung
Manupak / IV. Balang
b. Bagian Selatan : Desa Rumah
Rih
c. Bagian Timur
: Sungai Buaya
d. Bagian Barat
: Desa Rumah
Rih /Tanjung Bampu

\subsection{Pariwisata di Desa Sibunga-bunga}

Pariwisata di Desa Sibunga-bunga mulai berkembang sejak dibukanya Danau Linting dan Goa Tao Delapan Puteri sebagai salah satu daya tarik wisata pada tahun 2012. Danau Linting masih dikatakan sebagai danau yang misterius dikalangan masyarakat karena sampai saat ini tidak diketahui asal usulnya. Begitu pula dengan Goa Tao Delapan Puteri yang merupakan goa yang dijadikan sebagai tempat pemandian delapan puteri yang sudah dikramatkan. Perkembangan Danau Linting dan Goa Tao Delapan Puteri ditandai dengan dibentuknya Kelompok Sadar Wisata (POKDARWIS) pada tahun 2012, penyediaan fasilitas pendukung pariwisata, serta didukung dengan partisipasi masyarakat dalam perkembangan pariwisata di Desa Sibungabunga.

\subsection{Perkembangan Pariwisata di Desa Sibunga-bunga}

Perkembangan pariwisata di Desa Sibunga-bunga diukur berdasarkan beberapa aspek diantaranya :

1. Tingkat Kunjungan Wisatawan
Belum adanya pengelolaan yang baik Danau Linting membuat tidak diketahuinya jumlah kunjungan wisatawan secara tertulis setiap bulannya. Namun, berdasarkan hasil wawancara dengan ketua POKDARWIS mengatakan bahwa jumlah kunjungan wisatawan meningkat cukup pesat sejak tahun 2012 hingga mencapai 2000 pengunjung setiap bulannya pada musim liburan seperti : Hari Raya Idul Fitri, Hari Raya Natal dan Tahun Baru, serta hari-hari besar lainnya. Tipelogi wisatawan yang datang ke Danau Linting masih didominasi oleh wisatawan domestik seperti wisatawan yang berasal dari Aceh, Palembang, Jakarta, maupun pengunjung lokal yang berasal dari dalam maupun luar Kabupaten Deli Serdang.

\section{Atraksi Wisata}

Desa Sibunga-bunga memiliki beberapa atraksi wisata alam diantaranya :

a. Danau Linting

Danau Linting merupakan salah satu danau dengan air hangat tetapi tidak berbau belerang seperti sumber mata air panas pada umumnya, sehingga menjadi daya tarik tersendiri bagi wisatawan. Selain itu, keunikan lain yang dimiliki Danau Linting adalah air danau yang berwarna hijau kebiruan, serta kedalaman dan juga asal usul danau yang masih menjadi misteri dikalangan masyarakat hingga saat ini.

b. Goa Tao Delapan Puteri

Goa Tao Delapan Puteri terletak tak jauh dari Danau Linting. Tempat ini memiliki keunikan karena Goa Tao Delapan Puteri bukan seperti goa pada umumnya. Goa Tao Delapan Puteri memiliki dua makna yaitu Goa dan Tao Delapan Puteri, goa yang dimaksud disini adalah Goa Perak dan Goa Emas. Goa Perak dikenal sebagai goa kakek yang dahulunya diyakini dijaga oleh seekor naga, sedangkan Goa Emas dikenal dengan goa nenek yang diyakini dahulunya dijaga oleh seekor ular. Kedua goa tersebut memiliki keunikannya masing-masing, dimana pada dinding goa terdapat butiran emas dan perak sesuai dengan nama pada masing-masing goa. Selain itu keunikan lain terdapat pada suhu goa yang bebanding terbalik satu dengan yang lainnya, padahal kedua goa terletak bersebelahan. Dimana Goa Perak memiliki suhu yang panas sedangkan Goa Emas memiliki suhu yang dingin dan sejuk. Selain itu Tao Delapan Puteri juga 
memiliki arti tersendiri dimana Tao dalam bahasa Batak berarti danau atau tempat pemandian. Jadi Tao Delapan Puteri dapat diartikan sebagai Danau Delapan Puteri yang merupakan tempat pemandian delapan putri diantaranya : Putri Hijau, Putri Laut, Putri Kasih, Beru Sembiring, Beru Tarigan, Beru Karo, Beru Perangin-angin, dan Beru Ginting.

3. Fasilitas Pariwisata

Berkembangnya pariwisata di Desa Sibunga-bunga membuat berkembangnya pula fasilitas -fasilitas pendukung pariwisata pada daya tarik wisata yang ada di Desa Sibungabunga. Adapun fasilitas yang disediakan guna untuk memenuhi kebutuhan wisatawan diantaranya : Tempat Parkir, Toilet Umum, Tempat Ibadah, serta fasilitas Warung dan Pondok Wisata yang disediakan oleh masyarakat Desa Sibunga-bunga untuk memenuhi kebutuhan wisatawan.

4. Partisipasi Masyarakat

Desa Sibunga-bunga menjadi salah satu daerah tujuan wisata yang telah didukung dengan partisipasi masyarakat dalam upaya pengembangan pariwisata di Desa Sibungabunga. Bentuk-bentuk partisipasi masyarakat dapat terlihat dari penyediaan fasilitas seperti warung dan juga pondok wisata yang disediakan oleh masyarakat Desa Sibungabunga. Bentuk partisipasi lainnya dapat dilihat dari adanya aturan ataupun larangan untuk memanjat pohon ataupun melompat dari pohon yang dibuat atas inisiatif masyarakat untuk menghindari terjadinya kerusakan lingkungan akibat prilaku buruk wisatawan.

Berdasarkan uraian diatas jika dikaitkan dengan Teori Tourism Area Life Cycle (TALC) oleh Butler, maka dapat disimpulkan bahwa perkembangan pariwisata berada pada tahap Involvment (keterlibatan). Hal tersebut sesuai dengan indikator pada Teori Tourism Area Life Cycle (TALC) yang ditandai dengan meningkatnya jumlah kunjungan wisatawan yang diperkirakan mencapai 2000 pengunjung setiap bulannya pada musim liburan seperti : Hari Raya Idul Fitri, Hari Raya Natal dan Tahun Baru, serta hari-hari besar lainnya. Kemudian, mulai adanya berbagai fasilitas pendukung pariwisata seperti tempat parkir, toilet umum, tempat ibadah maupun warung dan juga pondok wisata, serta adanya partisipasi masyarakat lokal.

\subsection{Implikasi Perkembangan Pariwisata Terhadap Sosial Ekonomi Masyarakat di Desa Sibunga-bunga}

Adapun berbagai implikasi dari perkembangan pariwisata di Desa Sibungabunga yang ditinjau dari aspek sosial ekonomi masyarakat diantaranya :

1) Peluang Kerja

Pariwisata memberi implikasi positif bagi perekonomian masyarakat di Desa Sibunga-bunga salah satunya adalah dengan membuka lapangan pekerjaan bagi masyarat sehingga menekan angka pengangguran di Desa Sibunga-bunga. Pariwisata memberikan penghasilan tersendiri bagi masyarakat yang awalnya memiliki pekerjaan yang tidak tetap seperti buruh, tukang becak, supir angkot maupun yang tidak memiliki pekerjaan sama sekali. Masuknya pariwisata memberi peluang tersendiri bagi masyarakat untuk mendapat pekerjaan yang lebih baik seperti menjadi pengurus POKDARWIS, Pedagang, maupun penyewa pondok wisata.

2) Pelanggaran aturan

Tidak dapat dipungkiri bahwasannya perkembangan pariwisata juga menimbulkan berbagai implikasi negatif diantaranya adalah pelanggaran aturan. Pelanggaran aturan yang ditetapkan oleh pengelola daya tarik wisata. Adapun aturan tersebut diantaranya adalah aturan dalam mendirikan bangunan yang mana bangunan harus memenuhi syarat : bangunan merupakan bangunan tidak permanen atau dapat dibongkar apabila pemerintah ingin mendirikan bangunan ditempat yang bersangkutan, kemudian bangunan harus berada pada radius kurang lebih $100 \mathrm{~m}$ dari batas (pagar pembatas) yang telah ditentukan, kemudian untuk alasan keselamatan dan kenyamanan bersama pengunjung dilarang untuk membawa barang bawaan melewati batas yang telah ditentukan dan juga mandi di danau dengan menggunakan sabun. Namun, pada kenyataannya aturan tersebut tidak sepenuhnya dijalankan oleh masyarakat maupun pengunjung. Hal tersebut terlihat dari masih banyaknya bangunan pondok wisata yang masih berada pada radius kurang dari $100 \mathrm{~m}$ atau bahkan hanya berjarak beberapa meter saja di batas yang 
telah ditentukan, sehingga mengganggu kenyamanan pengunjung karena bangunan tersebut didirikan di area yang seharusnya digunakan untuk berjalan kaki mengelilingi danau. Bentuk pelanggaran aturan lainnya berkaitan dengan keselamatan dan keindahan lingkungan yang dapat dilihat dari banyaknya pedagang yang mengizinkan pengunjung duduk dengan menggunakan kursi diareal danau. Hal tersebut jelas beresiko bagi keselamatan dan juga keindahan lingkungan, mengingat adanya larangan bagi pengunjung untuk membawa barang bawaan mereka memasuki areal danau. Selanjutnya pelanggaran aturan dapat terlihat dari adanya pedagang yang menggunakan sepeda motor menjual barang dagangannya di areal yang seharusnya digunakan oleh pengunjung untuk berjalan kaki, hal ini tentu saja mengganggu kenyamanan pengunjung. Hal lain yang menarik perhatian adalah pelanggaran aturan yang dilakukan oleh pengunjung yang mandi di danau dengan menggunakan sabun, yang akhirnya akan berdampak pada pencemaran air dan tak jarang plastik sabun maupun shampo dibuang begitu saja di areal danau, sehingga mengakibatkan pencemaran lingkungan. Tidak adanya tindak tegas dari pihak pengelola membuat pelanggaran akan terus berkelanjutan.

3) Pendapatan Masyarakat

Masuknya pariwisata membuat sebagian masyarakat mulai meninggalkan sektor pertanian dan beralih ke sektor pariwisata sebagai pedagang dan penyewa pondok wisata. Hal ini dikarenakan pendapatan yang diterima dari sektor pariwisata lebih besar dari pada sektor pertanian. Masyarakat yang bekerja sebagai petani jagung misalnya, harus menunggu selama 70 hari dari awal proses pembibitan hingga masa panen. Dari satu bungkus bibit jagung yang ditamam, petani mendapatkan delapan karung jagung yang di hargai sebesar Rp.150.000/ karung jagung. Jika ditotalkan dalam waktu 70 hari petani mendapatkan penghasilan sebesar $\mathrm{Rp}$. 1.200.000 / satu kali panen.

Beda halnya dengan pedagang yang memiliki empat sampai lima pondok wisata dan juga satu warung. Dimana satu pondok disewakan seharga Rp. 20.000 - Rp. 25.000 / pondoknya dan pedagang mampu menyewakan minimal tiga pondok per hari atau bahkan lima pondok pada saat musim liburan, sehingga pedagang mendapatkan penghasilan sebesar Rp. 75.000 / hari dari hasil penyewaan pondok dan Rp. 30.000 dari hasil berjualan makanan dan minuman, yang jika dijumlahkan pedagang mendapat penghasilan minimal Rp.3.000.000 / per bulan.

Dari penghasilan yang didapat sebagai pedagang dan penyewa pondok wisata, kesejahteraan masyarakat semakin meningkat. Masyarakat sudah tidak kesusahan dalam memenuhi kebutuhan pokok dan juga sudah bisa menyekolahkan anak-anak mereka hingga ke perguruan tinggi, serta masyarakat sudah mampu merenovasi rumah mereka menjadi lebih baik dan juga memperbaiki pondok-pondok yang sudah mulai rusak.

\section{SIMPULAN DAN SARAN \\ 5.1 Simpulan}

Perkembangan pariwisata di Desa Sibunga-bunga berada pada tahap involvement (keterlibatan). Hal tersebut sesuai dengan indikator pada teori Tourism Area Life Cycle (TALC) diantaranya dilihat dari tingkat kunjunjungan wisatawan yang meningkat hingga mencapai 2000 pengunjung per bulannya, adanya fasilitas penunjang pariwisata, serta adanya partisipasi masyarakat dalam pengembangan daya tarik wisata di Desa Sibunga-bunga.

Implikasi perkembangan pariwisata terhadap aspek sosial ekonomi masyarakat diantaranya : memberi peluang kerja yang lebih menjanjikan sebagai pengurus POKDARWIS, pedagang, maupun penyewa pondok wisata, timbulnya berbagai bentuk pelanggaran aturan yang ditetapkan oleh pengelola daya tarik wisata oleh masyarakat maupun oleh pengunjung itu sendiri sehingga menimbulkan ketidak nyamanan dan juga dapat berdampak pada kerusakan lingkungan di sekitar daya tarik wisata. Selain itu, pariwisata dapat meningkatkan pendapatan serta kesejahteraan masyarakat.

\subsection{Saran}

Berdasarkan hasil dan pembahasan yang telah dijabarkan diatas, maka saran untuk 
pemerintah agar lebih memperhatikan pembangunan pariwisata di Desa Sibungabunga, serta adanya pembenahan dan penambahan fasilitas pendukung pariwisata, juga harus adanya koordinasi antara pemerintah dengan masyarakat Desa Sibungabunga terkait dengan pengembangan pariwisata agar terciptanya pariwisata yang berkelanjutan.

Bagi pihak pengelola harus adanya ketegasan dalam hal penegakan aturan agar tidak terjadinya penyimpangan sosial dalam bentuk apapun dan juga harus adanya kesadaran dari masyarakat untuk sama-sama mentaati aturan dan juga menjaga ketertiban demi kenyamanan bersama.

\section{DAFTAR PUSTAKA}

Barus, S. I. P., Patana, P., \& Afifuddin, Y. (2013). Analisis Potensi Obyek Wisata dan Kesiapan Masyarakat dalam Pengembangan Desa Wisata Berbasis Masyarakat di Kawasan Danau Linting Kabupaten Deli Serdang. Peronema Forestry Science Journal, 2(2), 143-151.

Bungin, Burhan H,M, 2007. Penelitian Kualitatif : Komunikasi, Ekonomi, Kebijakan Publik, dan Ilmu Sosial. Jakarta:Kencana Prenama Media Group.

Gunawan, Imam. 2015. Metode Penelitian Kualitatif. Jakarta:Bumi Aksara.

Hartono, T. T., \& Purnomo, A. H. (2012). Sosial Ekonomi Masyarakat Perikanan.

Ibrahim. M. A. 2015. Metodelogi Penelitian Kualitatif. Jakarta:Bumi Aksara

Indrawan dan Yaniawati. 2014. Metodelogi Penelitian Kuantitatif, Kualitatif, dan Campuran. Bandung:PT. Refika Aditama

Jahja, Yudrik. 2011. Psikologi Perkembangan Edisi Pertama. Jakarta: Kencana

Permilasari, Ni Komang. 2014. Implikasi Perkembangan Pariwisata Terhadap Eksistensi Subak Canggu di Desa Canggu Kabupaten Badung. Skripsi. Fakultas Pariwisata

Pitana, I. G., \& Gayatri, P. G. (2005). Sosiologi pariwisata.Yogyakarta: Andi.

Soekanto, Soejono. 2005. Sosiologi Suatu Pengantar. Jakarta: Raja Grafindo Persada

Sugiyono. 2014. Metode Penelitian Kuantitatif, Kualitatif dan $R \& D$. Bandung:Alfabeta.

Suwena, I. K., Widyatmaja, I. G. N., \& Atmaja, M. J. (2010).Pengetahuan Dasar Ilmu Pariwisata. Udayana University Press.

Yusuf, A Muri. 2014. Metode Penelitian Kuantitatif Kualitatif dan Penelitian Gabungan. Jakarta:Prenada Media Group 